\title{
Human resource for health policy interventions towards health sector reform in a Zimbabwean peri-urban community: A Decision Space Approach
}

\author{
Bernard Hope Taderera ${ }^{a, b,{ }^{*}}$, Stephen James Heinrich Hendricks ${ }^{a}$ and Yogan Pillay ${ }^{c}$ \\ aschool of Health Systems and Public Health, University of Pretoria, Pretoria, South Africa; \\ ${ }^{b}$ Department of Political and Administrative Studies, University of Zimbabwe, Harare, Zimbabwe; \\ ${ }^{\mathrm{C}}$ National Department of Health of the Republic of South Africa, School of Health Systems and Public Health, University of Pretoria, Pretoria, \\ South Africa \\ ${ }^{*}$ CONTACT: Bernard Hope Taderera, School of Health Systems and Public Health, University of Pretoria, 31 Bophelo Road, Gezina, Pretoria 27, \\ South Africa, email: HTaderera@gmail.com
}

\begin{abstract}
Background: Human Resources for Health $(\mathrm{HRH})$ are important towards attainment of the health sector reform goal of universal health coverage in resource-constrained health systems. We used the Decision Space Approach to analyse decision space, innovation, and change in $\mathrm{HRH}$ reform policy interventions in Epworth, a peri-urban community in Zimbabwe. Methods: The study design was exploratory and cross-sectional. In this, we firstly explored the healthcare worker reform policy at the principal level to determine the main policy result areas. Findings enabled us to develop an $\mathrm{HRH}$ Decision Space Mapping Analysis Conceptual Tool consisting of six main policy result areas. We then used it to analyse decision space, innovation, and outcomes towards healthcare worker reform at the agent level in Epworth. Interpretive thematic analysis and descriptive statistics were used to facilitate analysis. Findings: Narrow decision space and functional innovation in the context of moderate decision space helps not only initiate healthcare worker reform interventions but also mitigate local incapacities to sustain the process. Future research may adopt the Conceptual Tool developed to facilitate analysis of decision space, innovation, and outcomes in local health systems focusing on the six policy result areas towards the health system reform goal of universal health coverage.
\end{abstract}

\section{KEYWORDS}

Human resource for health; policy; interventions; peri-urban; community; decision space; approach

\section{Introduction}

Human Resources for Health (HRH) reform policy interventions are an important aspect of the Health Sector Reform Agenda in resource-constrained systems $[1,2]$. Not only does it help address the global workforce crisis revealed by the 2006 World Health Report but also contributes towards the policy outcomes articulated by the World Health Report of December 2016, and the 2030 Global Strategy on Human Resources for Health [3-5]. Healthcare worker reform also contributes towards the universal health coverage goal stated in resolution WHA67.24 on Follow-up of the Recife Political Declaration on Human Resources for Health of May 2014 [6,7]. The attainment of Sustainable Development Goals, particularly goal number 11 , aimed at making cities and human settlements inclusive, safe, resilient, and sustainable, and goal number 3 , towards ensuring healthy lives and promoting well-being for all at all ages, is also dependent on health personnel reform in local communities $[7,8]$. Global progress towards health system reform presents an opportunity to reinforce effort towards equity in distribution, availability, accessibility, competency, compensation, and motivation of health human resources in limited resource areas $[1,5]$.

The Decision Space Approach developed by Prof Thomas Bossert of the Harvard School of Public Health presents one avenue through which reinforcement of the health sector reform effort in peri-urban areas may be made. This approach, outlined in Figure 1, facilitates analyses of decision space, innovation, and change in health sector reform policy interventions $[9,10]$. It has contributed towards health sector reform in a number of countries amongst which include Bolivia, Chile, Colombia, Fiji, Pakistan, Philippines, Uganda, and Zambia [10-13]. In these studies, analysis of result areas of the human resource functions that include salaries, contracts, and civil service presents an opportunity to understand HRH policy interventions further in resource incapacitated communities.

Decision space is the amount of decision-making authority (range of effective choice making) shared between the principal (national government) and the agent (local government) in health sector reform policy $[11,12]$. This decision space can be wide, moderate or narrow. Wide decision space is decentralized decision-making authority in which the principal 


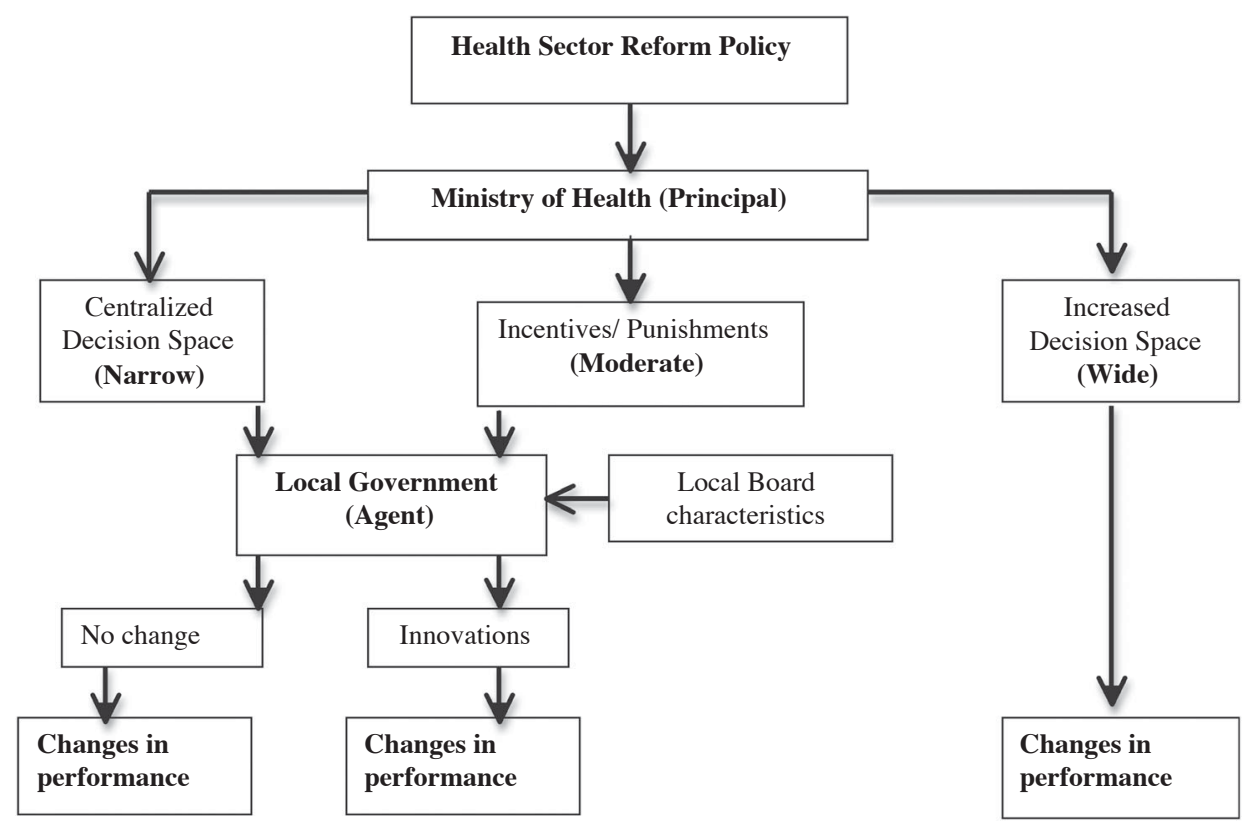

Figure 1. The Decision Space Approach. Source: Bossert (1998) [12] .

allows the agent total discretion. It enables actors to maximize their decision space through functional innovation. Moderate decision space is conditional decision-making authority in which incentives and punishments (the risk of sanction) are used to influence local choices. Narrow decision space is centralized decision-making authority in which the principal (central government) retains all decision-making authority [12]. The indicators of decision space include laws and regulations (and national court decisions), political rules of the game, administrative norms and standards, and the financial and technical capacity to enforce decisions. The actual (formal or informal) decision space may also be defined by a lack of enforcement of these formal definitions that allows lower level officials to bend the rules. Characteristics of the agent are capacity factors and contexts that influence their ability to make and implement choices. Changes in performance are the outputs and outcomes of decisions by actors $[11,12]$.

In this study, our aim was to use the Decision Space Approach to determine how HRH reform policy interventions of post-2008 impacted Epworth, a peri-urban community in south-east Harare, Zimbabwe. To achieve this aim, we sought to: (i) develop an $\mathrm{HRH}$ Decision Space Mapping Analysis Conceptual Tool based on Zimbabwe's healthcare worker reform policy and (ii) use the Conceptual Tool to facilitate analysis of decision space, local innovations, and changes in each of the six policy result areas in Epworth, Zimbabwe [11]. Our study contributes towards reinforcing effort initiated by the Global Health Workforce Alliance in 2008 to address the global workforce crisis, and attainment of the universal health coverage goal set by the United Nations General Assembly, and the Sustainable Development Goals [2-8].

\section{Methods and tools}

\section{Research design and study area}

The survey design used was exploratory and cross-sectional. In this, qualitative methods were used in the collection, presentation, and analysis of primary data. Secondary data, however, included quantitative data that enabled cross-verification towards generating a more comprehensive, reliable, and valid dataset $[14,15]$. Data were collected at the principal and agent levels. Fieldwork and data collection were carried out between July and December 2015 in Epworth, a peri-urban area located in south-east Harare, Zimbabwe. Epworth is made up of seven wards. In these wards, there are ten local clinics, comprising two municipal, one mission, and seven private clinics [16].

\section{Data collection at the principal level}

At the principal level, we started by carrying out a documentary search of HRH policy documents in to explore the reform policy agenda and decision space [17]. This enabled us to develop an interview guide that we then piloted in through two key-informant interviews with policy-makers drawn from the Ministry of Health $(\mathrm{MoH})$, and Health Services Board (HSB). The interview guide was then refined and used in five key-informant interviews with purposively selected policy-makers drawn from the MoH, the HSB, the Provincial Medical Office of Mashonaland East (PMOME), and the Zimbabwe Association of Church Hospitals $(\mathrm{ZACH})$ to explore the reform policy agenda and decision space further. A notebook, pen, and audio digital recorder were used to facilitate data collection and storage. Qualitative data were collected until saturation was reached [15,17]. Findings at this stage 
revealed six main policy result areas. From this, an HRH Decision Space Mapping Analysis Conceptual Tool was developed to facilitate analysis of decision space, innovation, and change in each policy result area at the agent level.

\section{Collection of data at the agent level}

A documentary search was conducted to determine the sampling frame and changes in staffing levels at each local clinic before and after 2009 at this level. From this, we established that there were three main categories of potential participants namely: (i) local community health officers and/or healthcare personnel managers (sisters in charge); (ii) healthcare workers; and (iii) community members that also included community health volunteers.

i Using the first two in-depth interviews with participants drawn from the first category, we piloted and refined our interview guide so as to determine decision space, local innovations, and changes in each of the six policy result areas [10]. From this, we refined the interview guide that we then used in eight more in-depth interviews carried out with local community health officers and/or healthcare personnel managers (sisters in charge) at each local health facility to determine decision space, local innovations, changes and implications towards universal health coverage in this community. Data from the interviews with local community health officers and/or healthcare personnel managers (sisters in charge) were then used to refine the semi-structured questionnaire used in the wider $\mathrm{PhD}$ study to determine the impact (changes) of decision space on local healthcare personnel $[14,15]$.

ii These semi-structured questionnaires were then piloted and further refined from three pilot semistructured interviews with healthcare workers. From this, we then extracted qualitative data from a sample of 21 semi-structured interviews carried out from the wider $\mathrm{PhD}$ study at local clinics across Epworth community to determine the impact of decision space in each key policy result area on health personnel [14]. The sampling frame for these semi-structured interviews consisted of two main categories of health cadres namely medical and non-medical personnel. The medical personnel included Nurses (Registered General Nurses, State Certified Nurses, Midwives and Primary Care Nurses), whilst non-medical personnel were Nurse Aides, Primary Counsellors, Environmental Health Officers, Pharmacy and Laboratory Technicians. The sample size of 21 was determined by the point at which saturation was reached. This then enabled us to refine the interview guide for Focus Group Discussions (FGDs) with community members [17].

iii For this category, we firstly piloted the interview guide in two FGDs [15]. The interview guide was then used in five more FGDs carried out with community members that also included community health volunteers. In this, we sought to determine the impact of decision space on service delivery and implications towards universal health coverage [17].

\section{Presentation of results}

Qualitative data were transcribed, coded, and presented in a narrative form. The codes were then grouped into four main themes around the healthcare worker reform policy result areas identified [14]. Quantitative data on changes in staffing levels were presented numerically and tabulated. Qualitative and quantitative data were integrated to help make the dataset comprehensive, validate, and reliable $[15,17]$.

\section{Data analysis and triangulation}

The Decision Space Approach was used to analyse findings using the HRH Decision Space Mapping Analysis Conceptual Tool. Descriptive statistics were used to interpret quantitative data, whilst interpretive thematic analysis was used for qualitative results $[14,15]$. Analysis sought to interpret decision space, innovations, and changes. Qualitative and quantitative data were integrated complementary and more comprehensive analysis [17].

\section{Institutional and ethical clearance}

Institutional and ethical clearance was sought and granted. Informed consent to participate, and for publication of findings was also sought and granted by all participants [14].

\section{Results}

\section{Levels of decision-making and the regulatory framework}

Figure 2 shows that decision-making in the implementation of healthcare worker reform policy interventions was made at two levels namely the Principal and the Agent.

Decision actors at the principal level consisted of an HRH Taskforce that had structures at the national and provincial level that were decentralized through deconcentration, and also included the district. These actors included the $\mathrm{MoH}$, government Ministries, PMOME, Seke District Medical Office, and the Zimbabwe United 


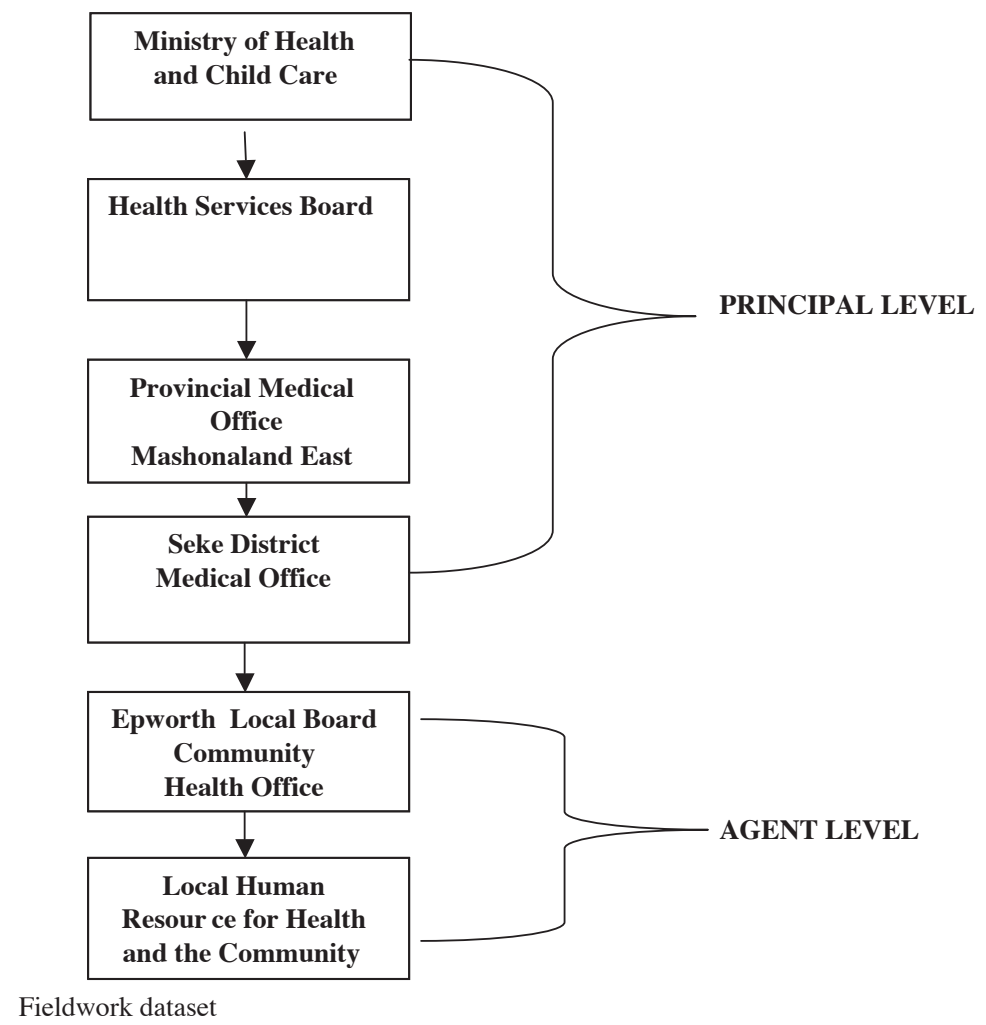

Figure 2. The organizational structure and decision-making levels.

Nations Development Assistance Framework (ZUNDAF). The Epworth Local Board had devolved municipal authority at the agent level, within which there were two public clinics, a Church Mission clinic, and seven local private clinics.

\section{Reform policy result areas and decision space}

It was established from key informants and a documentary search at the principal level that reform was implemented through the 2009 HRH Policy implemented through the HRH Strategic Plan of 2009-2014 [18,19]. Findings revealed six main policy result areas that included: Human Resource Planning and Budgeting; Recruitment, Training and Development; Deployment, Retention and Performance Management; Labour Relations; Health and Safety; and Human Resource Information Systems and Research [19]. In addition, we also established that each of these six result areas had sub-policy result areas. From this, we created the HRH Decision Space Mapping Analysis Conceptual Tool shown in Table 1 through which analysis of decision space, innovation, and change was then made.

\section{Ministerial intervention and collaboration with local actors}

Key informants revealed that capacity constraints that emanated from the 2007-2008 economic challenges resulted in the $\mathrm{MoH}$ intervening to collaborate with the Local Board in the policy result area of Human Resources Planning and Budgeting. Intervention provided the incentive of collaboration between the principal and the agent that revived Human Resource Planning, and Budgeting. However, we also established that the extent to which the $\mathrm{MoH}$ could successfully intervene was undermined by financial constraints and competing national socio-economic priorities amongst which included the Staff Monitored Programme.

\section{Overcoming local incapacity through innovative decision-making by the centre}

To mitigate capacity constraints, the $\mathrm{MoH}$ used centralized decision-making authority to innovate by engaging international strategic partners in the context of ZUNDAF. The strategic partnerships helped revive the HRH reform policy effort in Epworth through programme-specific intervention on HIV/AIDS, TB, Malaria, and Maternal Health. We established from local health professionals that the payment of allowances denominated in United States Dollars from this partnership that started in 2008 was a key intervention that helped initiate the revival process $[16,20]$.

Equally important was capacity building towards training critical healthcare workers by the $\mathrm{MoH}$, and also through the Ministry of Higher and Tertiary Education. Training helped increase the deployment of more trained Nurses with basic and post-basic skills in Epworth. Regular training workshops facilitated by 
Table 1. The HRH decision space mapping analysis conceptual tool.

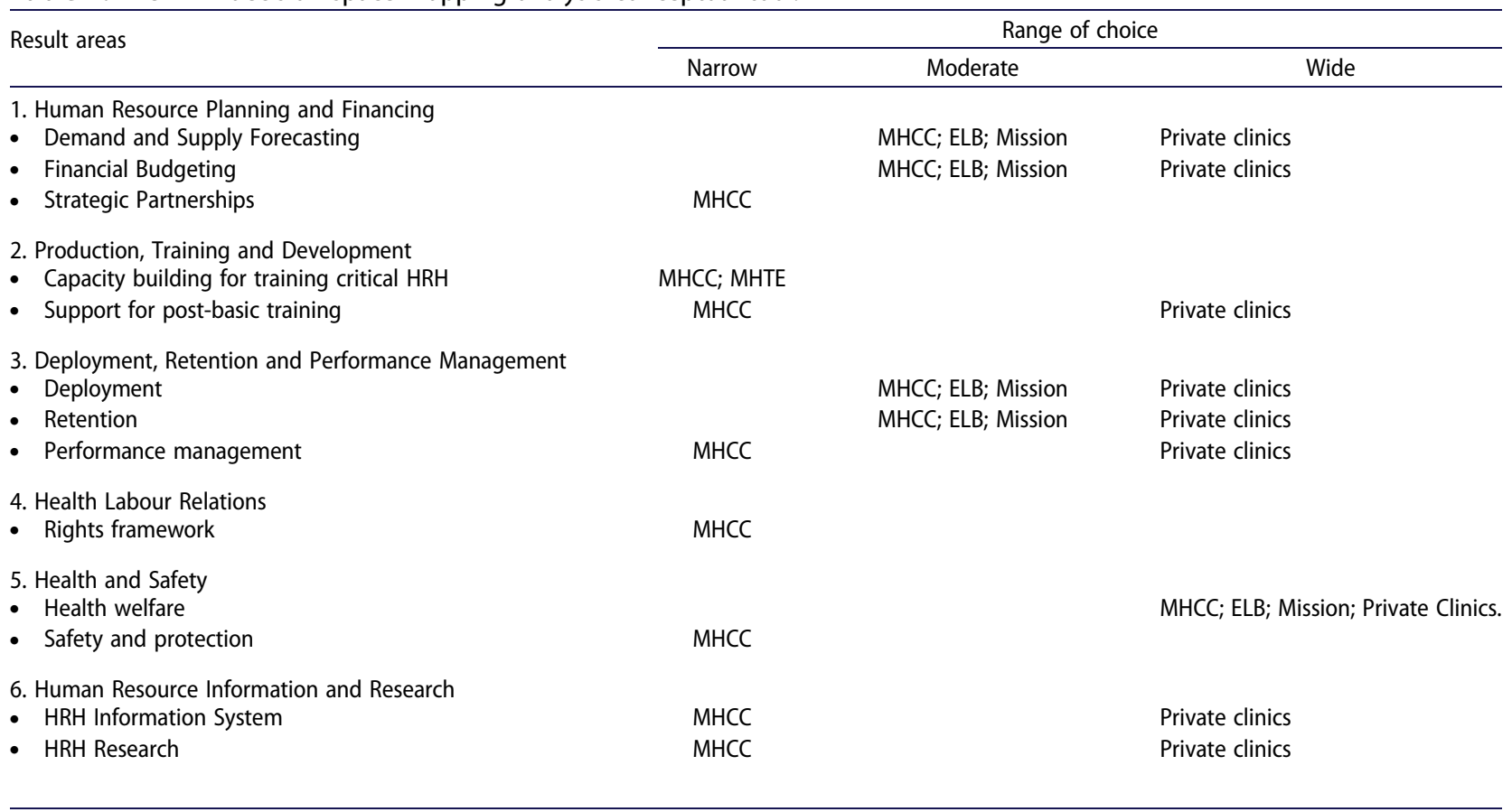

Note: Idea adapted from Bossert [11,12].

the $\mathrm{MoH}$ complemented this effort. Intervention by the $\mathrm{MoH}$ resulted in an increase in the number of Nurses (Registered General Nurses, Midwives, State Certified Nurses, and Primary Care Nurses) from 17 in 2007 to 56 in 2014. In addition, the number of non-medical personnel (Nurse Aides, Environmental Health Officers, Primary Counsellors, Pharmacy Technicians, Dispensary Assistants, Pharmacy Technicians, Ambulance Drivers, and Laboratory Scientists) also increased from 7 in 2007 to 45 in 2014. In addition, community engagement resulted in a pool of about 30 Village Health Workers/Community Health Volunteers and Peer Educators. Whilst this helped expand the human resource base, volunteers however complained of being short staffed and under equipped. It is also important to note that the private sector existed parallel to the public sector and contributed 11 out of the 56 Nurses, and 6 out of the 27 Nurse Aides [16] However, community members revealed that whilst the private sector provided an alternative option for healthcare, higher consultation fees with no option for free medical treatment and fixed operating times were barriers that undermined access. Health professionals at public clinics, however, revealed that this shifted the burden of disease to their facilities thereby resulting in heavier workload.

\section{The benefit of complementary decision-making authority}

To counter the effects of a heavier workload and worker shortages, we established from local key informants that the Epworth Local Board and Mission complemented the payment of salaries denominated in the
United States Dollar made by the MoH that started in 2009 by paying a salary top-up allowance, provision of residential stands, and local accommodation [21]. However, local capacity constraints undermined the extent to which the Local Board and Mission could complement effort by the $\mathrm{MoH}$ towards retention of personnel. For instance, healthcare workers revealed that the failure to provide retention incentives to all created a sense of division and undermined morale [16]. The lack of self-sustainability and incapacity to innovate meant government takeover was a possibility.

\section{Policy decision areas undermined by incapacity}

However, the possibility of this happening appeared limited by capacity constraints experienced in result areas where there was wide or narrow decision space [11]. For instance, wide decision space on health welfare was undermined by local financial constraints. On the other hand, narrow decision space on the safety protocol was undermined by what appeared to be limited enforcement that also resulted in inadequate clinical knowledge levels particularly amongst non-medical personnel about the safety protocol prescribed by the principal [16]. Apart from this, incapacity undermined the establishment of an Observatory for HRH Information and Research.

\section{Discussion}

The first theme is the importance of functional innovation to overcome local incapacities in policy result areas where either narrow or wide decision space is enjoyed [11]. Meaningful reform in healthcare depends 
on innovation. Functional innovation is the core and critical leadership competency for sustained superior performance [20]. It is creativity that enables actors to maximize their potential in their decision space in specific policy result areas [12]. In Epworth, the importance of functional innovation in policy result areas with narrow decision space was revealed in the subpolicy result area of Strategic Partnerships as shown in Table 1. Our findings revealed that functional innovation enabled the $\mathrm{MoH}$ to overcome its incapacity at the principal level by engaging international strategic health partners. In turn, this helped mitigate local capacity constraints and revived the HRH reform policy effort between 2009 and 2014 [16,21]. Revival of healthcare personnel reform interventions contributes towards the attainment of equity in distribution, availability, and accessibility in resource-constrained communities [5,7].

In addition, the $\mathrm{MoH}$ also innovated functionally to overcome shortages by building its capacity to train critical healthcare workers on its own and through the Ministry of Higher and Tertiary Education. Despite limited capacity to absorb them all into the public health sector, training helped improve the availability of skilled health professionals. In turn, this contributed towards the deployment of more skilled health professionals in Epworth. Improving the competency of health personnel helps contribute towards the outcomes set out in the 2030 Global Strategy on Human Resources for Health in low-resource areas [5].

The importance of functional innovation is also revealed by the failure to implement decisions because of capacity constraints in result areas where narrow or wide decision space is enjoyed $[10,11]$. In this regard, our second theme is the lack of capacity that undermines narrow or wide decision space in peri-urban areas. We established that capacity constraints undermined the implementation decisions in policy result areas with narrow decision space. As shown in Table 1, these policy result areas include Information and Research where capacity constraints undermined the establishment of the National Health Workforce Observatory, and Performance Management where the results based tool was not compatible with local contexts in Epworth. Capacity constraints also undermined the implementation of wide decision space in all policy result areas by the local private sector thus undermining the extent to which it could complement the local public sector. This has negative implications on the role of the private sector towards addressing the global workforce crisis, and attainment of the universal health coverage goal set by the United Nations in 2014, and the 2030 Sustainable Development Goals in resource-constrained areas [4-8].

Findings from our study showed that one of the strategies to mitigate capacity constraints is collaboration that enables complementary effort between the principal and agent in some HRH reform policy result areas. In this regard, this is our third theme. Collaboration is innovation that occurs in the context of moderate decision space where the principal uses incentives and/or punishments to influence decision-making by the agent. One of the incentives of moderate decision space is complementary intervention by the $\mathrm{MoH}$ that helps mitigate capacity constraints in a peri-urban community [11,12]. In Epworth, the principal provided this incentive through intervention that brought with it technical and financial benefits that helped revive HRH Planning and Financing, and Deployment and Retention. This helped increase the number of Nurses (Registered General Nurses, Midwives, State Certified Nurses, and Primary Care Nurses) from 17 in 2007 to 56 in 2014 as outlined in Figure 3. In addition, our findings also showed that the number of non-medical personnel (Nurse Aides, Environmental Health Officers, Primary Counsellors, Pharmacy Technicians,

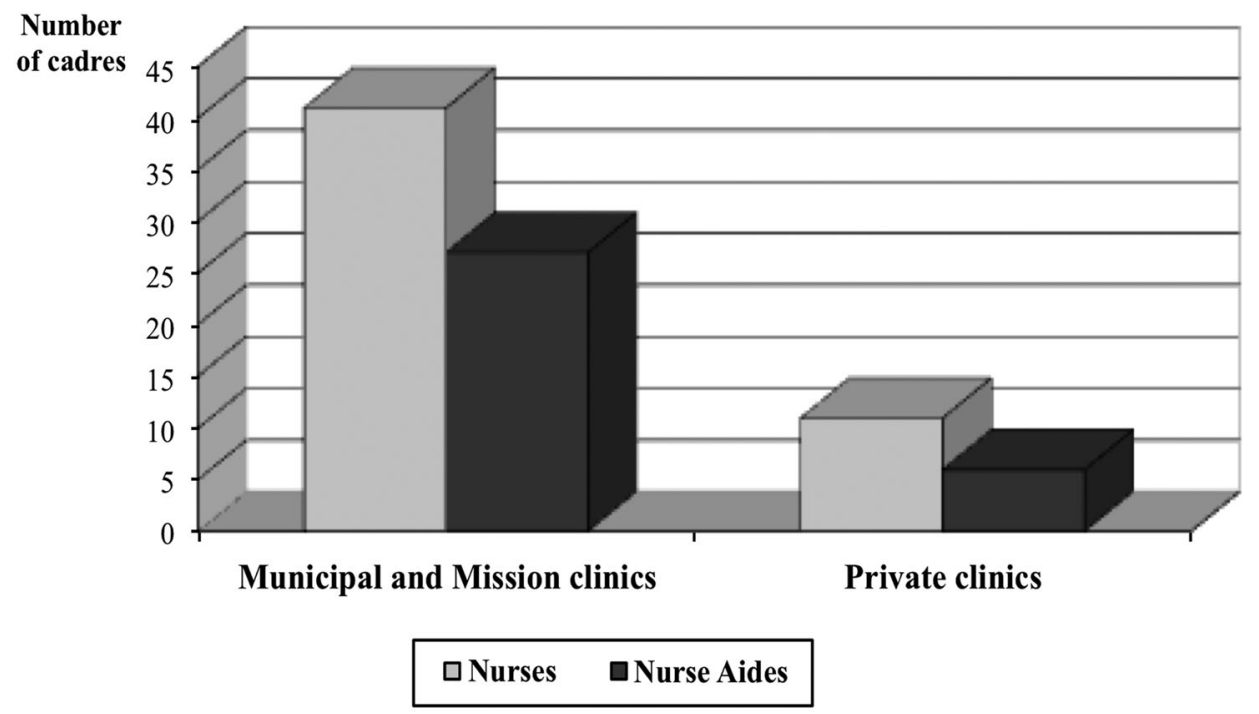

Figure 3. Human resource contributions by local sectors. Source: Taderera et al. [10]. 
Dispensary Assistants, Pharmacy Technicians, Ambulance Drivers, and Laboratory Scientists) also increased from 7 in 2007 to 45 in 2014 [16].

The community were also engaged and participated through a pool of about 30 Village Health Workers/ Community Health Volunteers and Peer Educators. The community contribute towards improved availability and accessibility of healthcare services because the public are also co-producers of health in the context of local decision space [9]. However, in order for community contribution to be more effective, efficient, and sustainable, there should be knowledge sharing and training. In Asia, the Bangladesh Rural Advancement Committee (BRAC) helped improve the competency of community health workers through knowledge sharing with healthcare workers at facilities and training towards mobile health improvement [22]. Apart from community participation, enabling local private sector participation resulted in a contribution of 11 out of the 56 Nurses, and 6 out of the 27 Nurse Aides as shown in Figure 3 [16]. Private sector participation help expand the local human resource base, which also help mitigate the health personnel shortages in low-income areas [4].

Our fourth theme is incapacity that reduces the risk of takeover. The risk of takeover exists if the principal has the potential to take over the local health system at the agent level [12]. In Epworth, the takeover would result in a shift from devolution to deconcentration which would result in a government takeover of the two Municipal clinics and one Mission clinic due to the lack of local self-sustainability. The takeover would result in a shift towards narrow decision space in all policy result areas [11]. However, capacity constraints due to competing priorities at the national level that also undermined the extent to which the state could successfully intervene in Epworth between 2009 and 2014 are a major stumbling block to the successful takeover.

\section{Conclusions}

Our results concluded that the universal health coverage goal of health sector reform in peri-urban communities can be achieved through analysis of decision space, innovation, and change in the six result areas of HRH reform policy. Using the HRH Decision Space Mapping Analysis Conceptual Tool developed from this study, we concluded that: (i) functional innovation is important towards mitigating capacity constraints in policy result areas with either narrow or wide decision space; (ii) whilst moderate decision space may result in the risk of sanction through possible takeover, it provides the incentive of collaboration which enables the expansion of the resource base to mitigate capacity constraints; and (iii) whilst the risk of sanction through possible takeover by the principal is a possibility, capacity constraints and other competing interests at this level may also undermine the extent to which desired outcomes may be successfully achieved. Our recommendation is that future research may adopt the HRH Decision Space Mapping Analysis Conceptual Tool that we developed to help analyse decision space, innovation, and change focusing on the six HRH reform policy result areas identified. We envisage that this will help contribute towards addressing the global health workforce crisis and attainment universal health coverage in periurban communities. However, future analysis of healthcare worker reform interventions using the Decision Space Approach in resource-constrained communities may also consider seven parameters to measure universal health coverage [7]. Future research may also consider the integration of clinical indicators towards quality measurement and improvement of healthcare services in low-resource communities towards the attainment of universal health coverage [23].

\section{Research in context}

\section{Evidence before this study}

Previous studies on health sector reform sought to emphasize the importance of HRH towards the attainment of universal health coverage. Progress made presented an opportunity to reinforce the reform effort in peri-urban communities. The Decision Space Approach developed by Prof Thomas Bossert of the Harvard School of Public Health presented one avenue through which reinforcement of the health sector reform effort in resource-constrained areas may be made. This approach has contributed towards health sector reform in a Bolivia, Chile, Colombia, Fiji, Pakistan, Philippines, Uganda, and Zambia. In these studies, analyses focused on result areas of the human resource policy functions that include salaries, contracts, and civil service. This presented an opportunity to understand $\mathrm{HRH}$ reform policy interventions in low-resource areas.

\section{Added value of this study}

Our findings revealed six policy result areas in which decision space, innovation, and change were analysed in Epworth using the HRH Decision Space Mapping Analysis Conceptual Tool. These included Human Resource Planning and Budgeting; Recruitment, Training and Development; Deployment, Retention and Performance Management; Labour Relations; Health and Safety; and Information Systems and Research. Our analyses revealed the importance of narrow decision space towards revival of the reform effort, and functional innovation to mitigate capacity constraints that might undermine HRH reform in resource-constrained areas. 


\section{Implications of all available evidence}

Future research may adopt the HRH Decision Space Mapping Analysis Conceptual Tool that we developed to help analyse decision space, innovation, and change focusing on the six HRH reform policy result areas identified. In this, analysis may consider the seven parameters to be considered when measuring universal health coverage, and quality measurement to effectively address the global health workforce crisis and attainment of universal health coverage in resource-constrained communities.

\section{Disclosure statement}

No potential conflict of interest was reported by the authors.

\section{Funding}

This study was funded by the African Population and Health Research Centre (APHRC) [Grant award number ADDRF 2015-2017 ADF 002].

\section{Notes on contributors}

Bernard Hope Taderera is postdoctoral researcher specialising in Health Policy and Management.

Stephen James Heinrich Hendricks is a Professor of Health Policy and Management at the University of Pretoria.

Yogan Pillay is a Doctor of Public Health. He is the Deputy Director-General at the National Department of Health, South Africa.

\section{References}

[1] Calciolari S, Ferrari D, Ortiz L, et al. Organizing healthcare in remote rural areas: comparing experiences of service delivery re-design. Int J Healthcare Manage. 2016;3[cited 2017 Nov 9]. Available from: http://www.tandfonline.com/doi/pdf/10.1080/20479700. 2015.1101939? redirect $=1$

[2] Dussault G, Dubois C. Human resources for health policies: a critical component in health policies. BMC Hum Resour Health. 2003;1[cited 2017 Nov 9]. Available from: http://www.human-resources-health. com/content $/ 1 / 1 / 1$

[3] Campbell J, Dussault G, Buchan J, et al. A universal truth: no health without a workforce. Forum report, third global forum on human resources for health, Recife, Brazil. Global Health Workforce Alliance and World Health Organization. 2013 [cited 2016 Dec 28]. Available from: http://www.who.int/workforceall iance/knowledge/resources/GHWA_AUniversalTruth Report.pdf

[4] Dussault G, Badr E, Haroen H, et al. Follow-up on commitments at the Third Global Forum on Human Resources for Health: Indonesia, Sudan, Tanzania.
BMC Hum Resour Health. 2016 [cited 2017 Nov 2]. Available from: https://human-resources-health.biom edcentral.com/articles/10.1186/s12960-016-0112-0

[5] World Health Organization. Global strategy on human resources for health: workforce 2030;2016. [cited 2017 Nov 2]. Available from: http://www.who.int/hrh/re sources/global_strategy_workforce2030_14_print.pdf

[6] Campbell J, Dussault G, Buchan J, et al. A universal truth: no health without a workforce. Forum report, third global forum on human resources for health, Recife, Brazil. Global Health Workforce Alliance and World Health Organization [cited 2017 Nov 3]. Available from: http://www.who.int/workforcealliance/ knowledge/resources/GHWA_AUniversalTruthReport. pdf

[7] Reddock J. Seven parameters for evaluating universal health coverage: including supply- and- demand perspectives. Int J Healthcare Manage. 2017 [cited 2017 Nov 10]. Available from: http://www.tandfonline. com/doi/full/10.1080/20479700.2017.1287981

[8] United Nations Development Programme. The 2030 Sustainable Development;2015 [cited 2017 Nov 8]. Available from http://www.undp.org/content/dam/ undp/library/corporate/brochure/SDGs_Booklet_Web_ En.pdf

[9] Lister G, Jakubowski E. Public engagement in health policy: international lessons. J Manage Marketing Healthcare. 2008 [cited 2017 Nov 9]. Available from: http://www.tandfonline.com/doi/abs/10.1179/mmh.200 8.1.2.154

[10] Bossert T. Decentralization of health systems in Latin America: a comparative study of Chile, Colombia, and Bolivia. Health Sect Reform Initiative. 2000 [cited 2017 Nov 3]. Available from https://www. hsph.harvard.edu/ihsg/publications/pdf/lac/Decentrali zation45.PDF

[11] Bossert T, Beauvais J, Bowser D. Decentralization of health systems: preliminary review of four country case studies. Partnerships Health Reform. 2000 [cited 2017 Nov 3]. Available from http://www.health systems2020.org/files/967_file_m6tp1.pdf

[12] Bossert T. Analysing the decentralization of health systems in developing countries: Decision space, innovation and performance. Soc Scie Med. 1998;47 (10):1513-1527.

[13] Mohammed J, North N, Ashton T. Decentralisation of health services in Fiji: a decision space analysis. Int J Health Policy Manage. 2015;5:173-181[cited 2017 Nov 3]. Available from http://www.sid.ir/en/ VEWSSID/J_pdf/5075520160304.pdf. doi:10.15171/ ijhpm.2015

[14] Babbie E. The practice of social research. London: Wadsworth Publishing Company; 2010.

[15] Bryman A. Social research methods. New York: Oxford University Press; 2001.

[16] Taderera BH, Hendricks S, Pillay Y. Health personnel retention strategies in a peri-urban community: an exploratory study on Epworth, Zimbabwe. BMC Human Resour Health. 2016;14:17[cited 2017 Nov 9]. Available from: https://human-resources-health. biomedcentral.com/articles/10.1186/s12960-016-0113z. doi:10.1186/s12960-016-0113-Z

[17] Moser C. Survey methods in social investigation. London: Heineman Educational Books; 2001.

[18] Health Services Board. Human resource for health policy. Harare: Ministry of Health and Child Welfare; 2009. 
[19] Health Services Board. Human resource for health strategic plan 2010-2014. Harare: Ministry of Health and Child Welfare; 2009.

[20] Rethmeier K. Innovation for healthcare reform: creating opportunities to explore, expand and excel. J Manage Marketing Healthcare. 2010 [cited 2017 Nov 11]. Available from: http://www.tandfonline.com/doi/ abs/10.1179/175330310X12665775636508

[21] Taderera BH, Hendricks SJH, Pillay Y. Health system reform in peri-urban communities: an exploratory study of policy strategies towards healthcare worker reform in Epworth, Zimbabwe. Glob Health Action. 2016;9:32219[cited 2017 Nov 10]. Available from http://www.globalhealthaction.net/index.php/gha/artic le/view/32219. doi:10.3402/gha.v9.32219.

[22] Ahmed T, Shirahada K. Toward a sustainable healthcare service system in a limited resource context: case study of Bangladesh rural advancement committee's healthcare system. Int J Healthcare Manage. 2017 [cited 2017 Nov 11]. Available from: http://www.tandfonline. com/doi/full/10.1080/20479700.2017.1389512

[23] Chuang S, Howley P. Strategies for integrating clinical indicator and accreditation systems to improve healthcare management. Int J Healthcare Manage. 2017 [cited 2017 Nov 11]. Available from: http://www.tandfonline. com/doi/abs/10.1080/20479700.2017.1300396 